"Incentives and Superstars on the LPGA Tour"

by

Francisco J. Peschiera, Peter Hans Matthews and Paul M. Sommers

June, 2002

MIDDLEBURY COLLEGE ECONOMICS DISCUSSION PAPER NO. 02-21

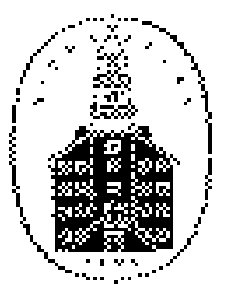

DEPARTMENT OF ECONOMICS

MIDDLEBURY COLLEGE

MIDDLEBURY, VERMONT 05753

http://www.middlebury.edu/ econ 


\section{Incentives and Superstars on the LPGA Tour}

$\begin{array}{lll}\text { Francisco J. Peschiera } & \text { Peter Hans Matthews(*) } & \text { Paul M. Sommers } \\ \text { Department of Economics } & \text { Department of Economics } & \text { Department of Economics } \\ \text { Middlebury College } & \text { Middlebury College } & \text { Middlebury College } \\ \text { Middlebury, VT 05753 } & \text { Middlebury, VT 05753 } & \text { Middlebury, VT 05753 }\end{array}$

First Draft: July 2001

Revised: October 2001

Under submission at Applied Economics

Abstract: Following Ehrenberg and Bognanno (1990a, b), this paper explores the role of incentives on the 2000 LPGA Tour. Overall, it finds them to have limited effectiveness. Several possible explanations are considered, including unmeasured differences in both abilities and courses and variations in the distribution of prizes across tournaments. The existence of a "superstar effect" is also considered.

JEL Classification Numbers: J33, L83

(*) corresponding author: 802/443-5591 (tel), 802/443-2084 (fax), pmatthew @ middlebury. edu 


\section{Incentives and Superstars on the LPGA Tour*}

\section{Introduction}

What motivates individuals to do well, particularly in environments where effort is difficult to observe or effort-based contracts are unenforceable? Are the financial incentives embodied within “tournaments" (Lazear and Rosen, 1990) sufficient? In recent years labor economists have studied professional sports tournaments to assess the incentive effects of prize money on player performance. Ehrenberg and Bognanno (1990a,b) focused on golf tournaments because of the ready availability of information on the incentive structure (both the total prize and its distribution) and individual output (players' scores). Using data from the 1984 men's Professional Golf Association (PGA) Tour as well as from the 1987 men's European PGA Tour, Ehrenberg and Bognanno find that higher prize levels do lead, ceteris paribus, to lower scores. In this paper, we ask whether or not the same incentive effects are present among women who competed on the 2000 Ladies Professional Golf Association (LPGA) Tour. We estimate a half dozen "benchmark models," and then consider the possible consequences of unmeasured differences in player ability and course difficulty, differences in responsiveness to incentives and the distribution of prizes, as well as the differences in incentives for men and women. We also investigate the existence of a possible "superstar effect" on the 2000 LPGA Tour.

\footnotetext{
* We wish to thank, without implication, Jeff Carpenter, Carolyn Craven, John Craven, Jon Isham, Bob Prasch and Scott Pardee for conversations about golf, incentives or both.
} 


\section{Methods and Data}

The framework used here is similar to that used by Ehrenberg and Bognanno. The player's score is affected by her effort or concentration level which in turn may be influenced by ultimate financial rewards, measures of the player's ability relative to her competitors' abilities, various tournament specific factors such as the difficulty of the course, and a random or luck component.

The typical tournament on the LPGA Tour involves four rounds. Half of the field is cut at the end of the second round. Following two more rounds of play, monetary prizes are awarded on the basis of the player's rank relative to the rest of the field. Of the thirty-six tournaments on the 2000 LPGA Tour, twenty-three were of this type. A complete list of the tournaments included in our sample, the total and first place prize monies disbursed in each tournament, and par and yardage for each course are presented in Table 1.

The LPGA Web site (www.golfonline.com/golfstats/lpgasearch.html) provides detailed round-by-round results for each 2000 LPGA tournament with final rank and prize money won by all players who completed four rounds of play. The data set consists of the top 50 money winners on the 2000 LPGA Tour. Our reliance on a subset of elite golfers is intended to mitigate the effects of the "marginal golfer" whose long run concerns with participation on the Tour mean that "the level and structure of prize money in a tournament may not be an accurate indicator of [her] marginal financial return to effort" (Ehrenberg and Bognanno, 1990a, 1311). ${ }^{1}$

\footnotetext{
${ }^{1}$ Ehrenberg and Bognanno use a larger sample, but draw a distinction between "exempt" and "non-exempt" players.
} 
The benchmark regression model (pooling the data across players and tournaments) is the following:

$$
\begin{aligned}
\operatorname{SCORE}_{i j}=\beta_{0} & +\beta_{1} \text { PRIZE }_{j}+\beta_{2} \text { MAJOR }_{j}+\beta_{3} \text { PAR }_{j}+\beta_{4} \text { YARDS }_{j} \\
& +\beta_{5} S A V E_{I}+\beta_{6} M S A V E_{j}+\mu_{i j}
\end{aligned}
$$

where the subindex $i j$ is for player $i$ in tournament $j$. And:

$$
\begin{aligned}
& S C O R E_{i j}=\text { four-round score of player } i \text { in tournament } j \\
& P R I Z E_{j}=\text { total prize money disbursed to all players in tournament } j \\
& M A J O R_{j}=\text { dummy variable for majors that takes the value } 1 \text { and } 0 \text { otherwise; } \\
& P A R_{j}=\text { the four-round par score for the tournament course; } \\
& Y A R D S_{j}=\text { the total course yardage in tournament } j ; \\
& S A V E_{i}=\text { player } i \text { 's four-round average score during the } 2000 \text { LPGA Tour; } \\
& M S A V E_{j}=\text { mean value of } S A V E_{i} \text { of all players who completed tournament } j \text {; and } \\
& \mu_{i j}=\text { random error term. }
\end{aligned}
$$

If there are incentive effects among women, then higher purse totals should lead to lower scores, and our estimate of $\beta_{1}$ should therefore be negative. Since winning a major usually means more prestige and recognition in the media, then the expected sign on $\beta_{2}$ should also be negative.

The expected signs for the coefficients on PAR and YARDS ( $\beta_{3}$ and $\beta_{4}$, respectively) should be positive. The more difficult the course, the higher the player's score. Player ability is proxied by SAVE. The better the player's overall performance on the 2000 LPGA Tour, the lower the player's score in any one tournament. Hence, we would expect $\beta_{5}>0$. Finally, the quality of the other players in the field is proxied by MSAVE, the mean value of 
$S A V E$ for all players who finished the tournament. If there are incentives for individuals to perform better in the face of tougher competition, then $\beta_{6}$ will be positive. If, however, the presence of a strong field increases the costs of concentration/effort too much, the result could be higher rather than lower scores (i.e., $\beta_{6}<0$ ). Dixit's (1987) model of strategic behavior in contests suggests that the sign of this coefficient could turn on the presence of an "odds-on favorite": under reasonable conditions, the absence of such a favorite is a sufficient condition for "overcommitment" by all participants. ${ }^{2}$

\section{Benchmark Results}

The least squares regression results for our benchmark model of the 2000 LPGA Tour are presented in Table 2. As anticipated, the more difficult the course (as measured by higher pars and longer yardage), the higher the player's score. The better the player (as measured by $S A V E$ ), the lower the player's score in any particular tournament. And, players' scores tend to be lower in majors, but not discernibly lower.

Curiously, higher purses seem to contribute to higher scores. Perhaps only the very best players are more responsive to financial incentives. But, we observe the same pattern of results for the top 20 and top 35 money winners as we do for the top 50 money winners.

\footnotetext{
${ }^{2}$ In this framework, "overcommitment" is the choice of an effort level in excess of that consistent with Nash equilibrium in the absence of opportunities for pre-commitment. In sports, Dixit $(1987,891)$ observes, such pre-commitment could be achieved by "merely psyching oneself up (or down).”
} 
Although the coefficient is statistically significant, its economic significance is a matter of debate: prize money would have to rise about $\$ 1.4$ million to increase a player's score by more than one stroke per round. Of the twenty-three tournaments included in our sample, only two had prize money totals in excess of $\$ 1.4$ million.

The competitive level of the rest of the field, measured by MSAVE, appears to hurt rather than help individual players. This pattern of results is remarkably consistent in all tournaments, majors and non-majors alike.

Four of the six tournaments on the 2000 LPGA Tour with purses in excess of $\$ 1$ million were majors. Hence, some of the curious results we ascribe to PRIZE may in fact be due to higher than average scores in majors. Yet, when the dummy variable defined for majors or individual scores in all four majors are excluded from the regression equation, the estimated coefficient on PRIZE remains positive and statistically significant. Even when we remove the individual observations for Karrie Webb, the top money winner in 2000, PRIZE is still directly related to SCORE.

IV. Elaborations on the Benchmark Model

To evaluate the robustness of these results - in particular, the positive PRIZE coefficient we considered several extensions of our benchmark model. The first of these were "variable coefficient" specifications, estimates of which are presented in Table 3. Following Ehrenberg and Bognanno (1990b), for example, the first column reports the estimates of a fixed effects model with golfer-specific intercepts, an attempt to capture otherwise unmeasured differences in skills. The coefficients on PAR, YARDS, SAVE and, most important, PRIZE are almost identical with those of our benchmark model, however, both in terms of size and 
statistical significance. There is a small increase in the size of the coefficient on MAJOR, but its p-value remains high - that is, well in excess of 0.50 . There is also some, but not much, effect on the MSAVE coefficient, and it remains significant: for a one stroke increase in the mean average of the "rest of the field," four-round scores are predicted to fall 3.10 rather than 2.97. Because the introduction of individual fixed effects had little effect on this model - the adjusted $\mathrm{R}^{2}$ falls, in fact, from 0.248 to 0.233 - or other specifications, further discussion of such effects is omitted.

The use of time or, in this context, course-specific fixed effects is also common with pooled data, and the second column in Table 3 reports the estimates for such a model. Three properties stand out: the adjusted $\mathrm{R}^{2}$ more than doubles, to 0.550 ; the coefficient on SAVE is almost identical in size but even more significant; and while the coefficient on PRIZE is also doubled, it is now insignificant at the 10 percent level. The first of these hints that PAR and YARDS do not capture all of the differences in courses, while the third suggests that if these differences are incorporated into the model, the effect of PRIZE on SCORE is muted. On the other hand, while the estimated coefficients on PAR, YARDS and MSAVE are close to their benchmark values, each is now insignificant at even the 50 percent level. Furthermore, each of the course coefficients is also insignificant. Our sense is that this reflects a more collinear set of independent variables and that, in practice, one must often choose between "behavioral variables" and course-based fixed effects.

Even in those cases where it is not quite significant, however, the positive coefficient on PRIZE remains a matter of concern, and it seems sensible to ask whether it reflects the presence of a few "influential” observations. To this end, we first allowed the PRIZE coefficient, rather than the intercept term, to differ across golfers, and the results are reported 
in the third column of Table 3 and Figure 1, a scatter plot of the 50 estimated PRIZE coefficients and their associated t-statistics. The adjusted $\mathrm{R}^{2}$ is smaller than in the benchmark model, but the non-PRIZE coefficients are similar in size and significance. More important, however, none of the estimated PRIZE coefficients was negative, and of the 50 positive coefficients, eight were significant at the 5 percent level, and one was significant at the 1 percent level. Furthermore, none of the coefficients exceeds 0.0065 , and most are clustered between 0.002 and 0.004 , so that, once more, even a $\$ 100,000$ increase in total purse is predicted to have a small effect on individual scores. The fourth column includes both variable PRIZE coefficients and course-specific intercepts, with similar results: all of the PRIZE coefficients are still positive, but just one of these is significant at the 5 percent level. Combined, the third and fourth columns nevertheless provide further evidence that the positive, albeit small, PRIZE coefficients in Table 2 are not a "statistical accident." Ehrenberg and Bognanno (1990a) observe that, in principle, both the total purse and its distribution will affect incentives, but note that on the PGA Tour, this structure was almost identical from one tournament to the next. There was not much variation in structure on the 2000 LPGA Tour either: of the twenty-three tournaments in our sample, all but five awarded the winner between 15.5 and 16.5 percent of the total purse. Of these five, one was more "egalitarian" - the Evian Masters, at 15 percent - while the other four (AFLAC Champions, 17.4 percent; U.S. Women's Open, 18.2 percent; Samsung World Championship, 22.4 percent; Arch Wireless Championship, 23.0 percent) were less so. Despite this small variation, we nevertheless attempted to determine whether our previous estimates of the PRIZE coefficient reflected variations in tournament structure. To this end, we separated the PRIZE variable into FIRST, the winner's purse measured in thousands of 
dollars, and OTHER, the difference between PRIZE and FIRST, and re-estimated some of the previous models. The results are reported in Table 4.

The first column is the benchmark specification with FIRST and OTHER substituted for PRIZE. We first note that the estimated coefficients on PAR, YARDS, SAVE and MSAVE are close to their previous values - the coefficient on MSAVE, which increases in size to -3.25 , is most affected - and remain significant, while the coefficient on MAJOR more than doubles in size, but remains insignificant. It is the coefficients on FIRST and OTHER that stand out, however: an increase in the prizes available to the "runners up" is estimated to increase SCORE even more than before -0.6 strokes per $\$ 100,000$, rather than 0.3 - but an increase in the first place prize is estimated to reduce four-round scores, at the rate of 1.3 strokes per $\$ 100,000$. (Some caution is called for here, however, since the coefficient on OTHER is statistically significant at the 5 percent level, while that on FIRST is significant at just the 20 percent level.) Furthermore, the hypothesis that the two coefficients are equal - a restriction that is implicit in the use of PRIZE in the previous models - can (just) be rejected at the 10 percent level. The estimates are also consistent with those for PRIZE alone: in the representative tournament, an increase of $\$ 100,000$ in the total purse means an increase of about $\$ 16,000$ in the winner's prize and $\$ 84,000$ in the prizes awarded to the rest of the field. The former is predicted to reduce SCORE 0.21 strokes and the latter, to increase it 0.52 strokes, with a combined effect of $-0.21+0.52=0.31$ strokes, which is almost identical to predictions based on PRIZE alone.

The results for two other "two prize models" suggest that these numbers be treated with some caution, however. The second column reveals, for example, that when fixed course effects are introduced, the coefficient on FIRST becomes positive once more. Its 
value is too large to be sensible, however, and more important, is also insignificant. As before, the addition of course-specific intercepts also overturns the significance of OTHER, PAR, YARDS and MSAVE coefficients. The third column omits these fixed effects, but allows the coefficients on FIRST and OTHER to vary across players, and Figure 2 is a scatter plot of the 50 pairs of estimates. The significance of the non-prize coefficients is restored, and their values are consistent with previous estimates. Figure 2 suggests the presence of a small number of outliers. In particular, while the mean estimated coefficient on FIRST is positive (0.159), the median is negative (-0.009). This pattern is reversed with the OTHER coefficients: the mean $(-0.025)$ is negative, and the median (0.006) is positive. We interpret this to mean that the behavior of the "median golfer" is consistent with the results in the first column.

Our tentative conclusion, therefore, is that the structure of tournament prizes matters in the case of the LPGA, but perhaps not in the sense that the Lazear and Rosen (1990) model predicts. In particular, the small, positive coefficient on OTHER, or on PRIZE in previous models, still needs to be rationalized. The simplest explanation, perhaps, is that financial rewards might stimulate workers to concentrate more, but among some professional athletes, notably the top money winners on the 2000 LPGA Tour, these rewards have little effect over a four-day tournament. That is, even when the coefficients on OTHER or PRIZE are significant, their estimated values are small, consistent with the notion that for most golfers, financial incentives had little effect on effort or concentration. This effect must be more pronounced in women than men, however, if it is to explain the differences between our results and Ehrenberg and Bognanno's. If so, female golfers, unlike their male counterparts, do not "hoard" effort in less lucrative tournaments. 
A related explanation is that for women golfers, the relation between compensation and incentives should perhaps be viewed in terms of a lifetime or career, not a single season. If changes in productivity are revealed slowly over a worker's lifetime, choosing a longer period may be the only way to show the efficacy of incentive schemes. After all, great oaks from little acorns grow but, as anyone who has ever watched a great oak grow, it is not a whoosh. In graphical terms, the relationship between each golfer's output (score) and total prize could be (almost) horizontal in one season, but still slope downward when data from several seasons are used.

A third possible explanation starts with the observation that the prizes available to women are much smaller than those available to men - the 25th place finisher at the 2000 US Women's Open, one of the LPGA's most lucrative tournaments, received $\$ 28,404$, while her counterpart at the US (Men’s) Open received \$45,537 - and that differences in endorsement opportunities exacerbate this "incentive gap." It is possible, then, that even among the LPGA elite, most will be reluctant to withhold or reduce effort in less lucrative tournaments and some will choose a more "defensive" or "cautious" approach in more lucrative tournaments. The former is consistent with a small PRIZE or OTHER coefficient, and the latter, with its nevertheless persistent positive sign.

The negative coefficient on MSAVE, viewed in the context of earlier Dixit's (1987) observations on the consequences of "odds-on favorites" in contests, leads to a fourth possible explanation, which we consider in more detail in the next section.

V. Was There A "Superstar Effect" in 2000? 
There is some reason to be concerned that the 2000 season is a special case, because of the presence of a "superstar" on the LPGA Tour. Karrie Webb participated in 16 of the 23 tournaments in our sample, and won 6 of them, including two majors, the Nabisco Championship and the U.S. Women's Open. She also finished fourth or better at three others, and earned \$1.876 million, 25 percent more than her closest rival, Annika Sorenstam, who won three tournaments of her own. Furthermore, this dominance was evident from the start: she won three of the first six tournaments in our sample.

Table 5 reports the results of our efforts to confirm, and perhaps measure, a possible "superstar effect" on the 2000 LPGA Tour. The entries in the first column, for example, are the estimated coefficients of our benchmark model for the seven tournaments in which Webb did not participate. (Since she participated in all four majors, that variable is now omitted.) The adjusted $\mathrm{R}^{2}$ is quite small (0.14) but the coefficient on PRIZE is now negative, substantial, and significant at the 5 percent level. In particular, in these tournaments, a $\$ 100,000$ increase in total purse is now predicted to reduce four-round scores two and a half full strokes, other things being equal. This was not the only sign to change, however: the coefficient on MSAVE is now positive and significant at the 1 percent level, which implies that in Webb's absence, a better field (lower MSAVE) produced lower scores, consistent with Dixit's (1987) results on the possible effects of favorites. Unfortunately, the coefficient on PAR also "flips": a one stroke increase in the four-round par is now associated with a one stroke reduction in scores, a counterintuitive result. The size and significance of the YARDS and SAVE coefficients remain more or less unchanged, however.

The second column reveals that these results do not survive the addition of coursespecific intercepts, however. The coefficients on PRIZE and MSAVE revert to their initial 
signs, but the former is now significant at the 10, not 1, percent level, and the latter becomes insignificant. Indeed, the coefficients on PAR, YARDS and MSAVE are all insignificant and, despite the increase in the adjusted $\mathrm{R}^{2}$, each of the course-specific coefficients is also insignificant on its own. Once more, it is unclear how much importance should be attached to these results, but we report them for the sake of completeness.

The estimates for the model in the third column, in which the course-based fixed effects are omitted but FIRST and OTHER are substituted for PRIZE, are more problematic. The coefficient on FIRST is negative, significant but implausible: an increase of $\$ 10,000$ in the winner's purse is now predicted to reduce four-round scores more than five full strokes, an almost nonsensical result. The coefficient on OTHER, 0.057, is somewhat more plausible, but the coefficient on PAR is once more negative. The constant, FIRST and OTHER are almost collinear in this truncated sample, however, and it is possible that a few influential observations have "contaminated" our estimates.

While the data are not conclusive, then, there is at least some evidence of a superstar effect on the 2000 LPGA Tour, an effect closer in spirit to Frank and Cook (1995) than, for example, Rosen (1981): the presence of the Tour's best player in a tournament appears to reduce, and in some cases reverse, the responsiveness of others to financial incentives. The implications for internal labor markets, where the use of tournament-based incentives is also common, are dramatic: where salespersons are compensated, at least in part, on the basis of relative output, or managers are promoted on the basis of relative performance, for example, the presence of a superstar could undermine otherwise effective incentive schemes.

\section{Conclusion}


The results presented in this paper suggest that, on the whole, total tournament prize money has a small effect on LPGA player performance, but in ways that were not at first anticipated. The total purse has just the opposite effect on scores of top money winners on the LPGA Tour that it has in men's PGA tournaments. On the LPGA Tour, higher total prize money does not lead to better (that is, lower) scores. This puzzling result is not easily explained. The possibilities considered here included unmeasured differences in player ability and/or course difficulty, differences in the responsiveness to financial incentives, the structure of these incentives, the choice of time horizon, the differences in incentives for men and women and last, the existence of a "superstar effect."

To these we should perhaps add one "non-economic" explanation. It is also possible that among even elite women golfers, money may not be the powerful motivator it is among men. Some workers seek job enrichment, with money, in the words of Kerr (1997), "merely a vestigial, low-order need that is or isn't met along the way." Our results are also consistent with the view that professional women golfers may more actively pursue other, loftier goals or less easily quantifiable nonfinancial rewards (recognition, performance feedback, greater responsibility) than their male counterparts. 


\section{REFERENCES}

Dixit, A. (1987) Strategic behavior in contests, American Economic Review, 77, 891-98.

Ehrenberg, R. G. and Bognanno, M. L. (1990a) Do tournaments have incentive effects? Journal of Political Economy, 98, 1307-24.

Ehrenberg, R. G. and Bognanno, M. L. (1990b) The incentive effects of tournaments revisited: evidence from the European PGA Tour, Industrial and Labor Relations Review, 43, 74-S - 88-S.

Frank, R. H. and Cook, P. J. (1995). The Winner-Take-All Society. Free Press, New York.

Kerr, S. (Ed.) (1997) Ultimate Rewards: What Really Motivates People to Achieve. Harvard Business School Publishing, Boston.

Lazear, E. P. and Rosen, S. (1990) Rank-order tournaments as optimum labor contracts, Journal of Political Economy, 89, 841-64.

Rosen, S. (1981) The economics of superstars, American Economic Review, 71, 845-58. 
Table 1. Four-Round LPGA Tournaments, 2000

$\begin{array}{lrrrr}\text { Name }^{\mathrm{a}} & \text { Purse }^{\mathrm{b}} & \text { First }^{\mathrm{c}} & \text { Par } & \text { Yardage } \\ \text { The Office Depot } & \$ 704.1 & 112.5 & 72 & 6297 \\ \text { Subaru Memorial of Naples } & 799.0 & 127.5 & 72 & 6328 \\ \text { Australian Ladies Masters } & 712.4 & 112.5 & 72 & 6300 \\ \text { Welch's/Circle K Championship } & 656.7 & 105.0 & 72 & 6222 \\ \text { Standard Register Ping } & 794.7 & 127.5 & 72 & 6392 \\ \text { Nabisco Championship } & 1200.6 & 187.5 & 72 & 6520 \\ \text { Longs Drugs Challenge } & 658.5 & 105.0 & 72 & 6388 \\ \text { The Philips Invitational } & 795.5 & 127.5 & 70 & 6101 \\ \text { Electrolux USA Championship } & 749.5 & 120.0 & 72 & 6431 \\ \text { LPGA Corning Classic } & 753.9 & 120.0 & 72 & 6062 \\ \text { Kathy Ireland Greens.Com Classic } & 704.1 & 112.5 & 72 & 6231 \\ \text { Wegmans Rochester International } & 943.5 & 150.0 & 72 & 6162 \\ \text { Evian Masters } & 1800.0 & 270.0 & 72 & 6091 \\ \text { McDonald's LPGA Championship } & 1308.9 & 210.0 & 71 & 6376 \\ \text { Jamie Farr Kroger Classic } & 940.1 & 150.0 & 71 & 6319 \\ \text { U.S. Women's Open } & 2744.4 & 500.0 & 72 & 6540 \\ \text { du Maurier Classic } & 1121.9 & 180.0 & 72 & 6403 \\ \text { Weetabix Women's British Open } & 1093.6 & 178.8 & 73 & 6285 \\ \text { Oldsmobile Classic } & 708.8 & 112.5 & 72 & 6191 \\ \text { New Albany Golf Classic } & 935.0 & 150.0 & 72 & 6279 \\ \text { Samsung World Championship } & 677.9 & 152.0 & 72 & 6378 \\ \text { AFLAC Champions } & 701.2 & 122.0 & 72 & 6231 \\ \text { Arch Wireless Championship } & 935.0 & 215.0 & 72 & 6497\end{array}$

${ }^{\mathrm{a}}$ Tournament names in italics are majors.

${ }^{\mathrm{b}}$ Total prize money disbursed (in thousands of dollars).

${ }^{\mathrm{c}}$ First prize money (in thousands of dollars). 
Table 2. Regression Results of Player Four-Round Scores, 2000 LPGA Tour

\begin{tabular}{|c|c|c|c|c|c|c|}
\hline $\begin{array}{c}\text { Explanatory } \\
\text { variable }\end{array}$ & $\begin{array}{c}\text { Top } 50 \\
\text { money } \\
\text { winners }\end{array}$ & $\begin{array}{c}\text { Top } 35 \\
\text { money } \\
\text { winners }\end{array}$ & $\begin{array}{c}\text { Top } 20 \\
\text { money } \\
\text { winners }\end{array}$ & $\begin{array}{c}\text { Top 50 } \\
\text { excluding } \\
\text { variable on } \\
\text { MAJOR }\end{array}$ & $\begin{array}{c}\text { Top } 50 \\
\text { excluding } \\
\text { Karrie } \\
\text { Webb }\end{array}$ & $\begin{array}{c}\text { Top } 50 \\
\text { excluding } \\
\text { observations } \\
\text { on MAJOR }\end{array}$ \\
\hline Constant & $\begin{array}{l}632.0 \\
(2.71)\end{array}$ & $\begin{array}{l}702.2 \\
(2.63)\end{array}$ & $\begin{array}{l}562.5 \\
(1.71)\end{array}$ & $\begin{array}{l}628.4 \\
(2.70)\end{array}$ & $\begin{array}{l}629.7 \\
(2.66)\end{array}$ & $\begin{array}{l}583.5 \\
(2.11)\end{array}$ \\
\hline PRIZE & $\begin{array}{l}.0028 \\
(4.16)\end{array}$ & $\begin{array}{l}.0033 \\
(4.31)\end{array}$ & $\begin{array}{l}.0024 \\
(2.44)\end{array}$ & $\begin{array}{l}.0027 \\
(4.79)\end{array}$ & $\begin{array}{l}.0028 \\
(4.13)\end{array}$ & $\begin{array}{l}.0039 \\
(3.24)\end{array}$ \\
\hline MAJOR & $\begin{array}{c}-.313 \\
(-0.33)\end{array}$ & $\begin{array}{c}-.948 \\
(-0.86)\end{array}$ & $\begin{array}{c}-.013 \\
(-0.01)\end{array}$ & & $\begin{array}{c}-.224 \\
(-0.24)\end{array}$ & \\
\hline$P A R$ & $\begin{array}{c}.364 \\
(2.88)\end{array}$ & $\begin{array}{c}.392 \\
(2.56)\end{array}$ & $\begin{array}{c}.302 \\
(1.51)\end{array}$ & $\begin{array}{c}.366 \\
(2.90)\end{array}$ & $\begin{array}{c}.362 \\
(2.84)\end{array}$ & $\begin{array}{c}.309 \\
(1.88)\end{array}$ \\
\hline YARDS & $\begin{array}{c}.014 \\
(6.04)\end{array}$ & $\begin{array}{c}.014 \\
(5.00)\end{array}$ & $\begin{array}{c}.015 \\
(4.00)\end{array}$ & $\begin{array}{c}.014 \\
(6.40)\end{array}$ & $\begin{array}{c}.014 \\
(5.94)\end{array}$ & $\begin{array}{c}.016 \\
(5.27)\end{array}$ \\
\hline SAVE & $\begin{array}{l}1.085 \\
(9.83)\end{array}$ & $\begin{array}{l}1.070 \\
(8.71)\end{array}$ & $\begin{array}{l}1.027 \\
(6.32)\end{array}$ & $\begin{array}{l}1.085 \\
(9.83)\end{array}$ & $\begin{array}{l}1.071 \\
(8.84)\end{array}$ & $\begin{array}{l}1.090 \\
(7.65)\end{array}$ \\
\hline$M S A V E$ & $\begin{array}{l}-2.970 \\
(-3.65)\end{array}$ & $\begin{array}{l}-3.222 \\
(-3.50)\end{array}$ & $\begin{array}{l}-2.619 \\
(-2.33)\end{array}$ & $\begin{array}{l}-2.953 \\
(-3.64)\end{array}$ & $\begin{array}{l}-2.946 \\
(-3.56)\end{array}$ & $\begin{array}{l}-2.787 \\
(-2.95)\end{array}$ \\
\hline Adjusted $R^{2}$ & .248 & .252 & .233 & .249 & .239 & .193 \\
\hline Sample size & 671 & 504 & 298 & 671 & 655 & 548 \\
\hline
\end{tabular}

Note: Numbers in parentheses are $t$-ratios. 
Table 3. Regression Results for Variable Coefficient Models

\begin{tabular}{|c|c|c|c|c|}
\hline $\begin{array}{l}\text { Fixed } \\
\text { Effects? }\end{array}$ & $\begin{array}{l}\text { Yes. } \\
\text { Players. }\end{array}$ & $\begin{array}{l}\text { Yes. } \\
\text { Courses. }\end{array}$ & No. & $\begin{array}{l}\text { Yes. } \\
\text { Courses. }\end{array}$ \\
\hline Constant & & & $\begin{array}{l}649.4 \\
(2.58)\end{array}$ & \\
\hline PRIZE & $\begin{array}{l}.0028 \\
(4.06)\end{array}$ & $\begin{array}{l}.0054 \\
(1.53)\end{array}$ & $\begin{array}{l}\text { Variable } \\
\text { See Fig. } 1\end{array}$ & Variable \\
\hline MAJOR & $\begin{array}{l}-.442 \\
(-0.46)\end{array}$ & $\begin{array}{l}-.773 \\
(-0.13)\end{array}$ & $\begin{array}{l}-.370 \\
(-0.38)\end{array}$ & $\begin{array}{l}-1.116 \\
(-0.12)\end{array}$ \\
\hline$P A R$ & $\begin{array}{l}.364 \\
(2.82)\end{array}$ & $\begin{array}{l}.467 \\
(0.52)\end{array}$ & $\begin{array}{l}.378 \\
(2.83)\end{array}$ & $\begin{array}{l}.528 \\
(0.55)\end{array}$ \\
\hline$Y A R D S$ & $\begin{array}{l}.014 \\
(5.90)\end{array}$ & $\begin{array}{l}0.009 \\
(0.50)\end{array}$ & $\begin{array}{l}.015 \\
(5.98)\end{array}$ & $\begin{array}{l}.008 \\
(0.38)\end{array}$ \\
\hline$S A V E$ & $\begin{array}{l}1.100 \\
(9.65)\end{array}$ & $\begin{array}{l}1.080 \\
(12.62)\end{array}$ & $\begin{array}{l}1.155 \\
(4.24)\end{array}$ & $\begin{array}{l}1.178 \\
(5.62)\end{array}$ \\
\hline$M S A V E$ & $\begin{array}{l}-3.096 \\
(-3.71)\end{array}$ & $\begin{array}{l}-4.103 \\
(-0.59)\end{array}$ & $\begin{array}{l}-3.128 \\
(-3.67)\end{array}$ & $\begin{array}{l}-4.373 \\
(-0.60)\end{array}$ \\
\hline Adjusted $\mathrm{R}^{2}$ & .233 & .550 & .201 & .533 \\
\hline Sample size & 671 & 671 & 671 & 671 \\
\hline
\end{tabular}


Table 4. Regression Results for "Two Prize" Specifications

\begin{tabular}{|c|c|c|c|}
\hline $\begin{array}{l}\text { Fixed } \\
\text { Effects? }\end{array}$ & No. & $\begin{array}{l}\text { Yes. } \\
\text { Courses. }\end{array}$ & No. \\
\hline Constant & $\begin{array}{l}702.8 \\
(2.97)\end{array}$ & & $\begin{array}{l}761.7 \\
(2.79)\end{array}$ \\
\hline FIRST & $\begin{array}{l}-.013 \\
(-1.35)\end{array}$ & $\begin{array}{l}4.46 \\
(0.50)\end{array}$ & $\begin{array}{l}\text { Variable } \\
\text { (See Fig. 2) }\end{array}$ \\
\hline OTHER & $\begin{array}{l}.0062 \\
(2.82)\end{array}$ & $\begin{array}{l}.0054 \\
(1.53)\end{array}$ & $\begin{array}{l}\text { Variable } \\
\text { (See Fig. 2) }\end{array}$ \\
\hline MAJOR & $\begin{array}{l}-.649 \\
(-0.68)\end{array}$ & $\begin{array}{l}-.774 \\
(-0.13)\end{array}$ & $\begin{array}{l}-1.098 \\
(-1.03)\end{array}$ \\
\hline$P A R$ & $\begin{array}{l}.362 \\
(2.87)\end{array}$ & $\begin{array}{l}.467 \\
(0.52)\end{array}$ & $\begin{array}{l}.383 \\
(2.78)\end{array}$ \\
\hline$Y A R D S$ & $\begin{array}{l}.016 \\
(6.21)\end{array}$ & $\begin{array}{l}0.009 \\
(0.50)\end{array}$ & $\begin{array}{l}0.016 \\
(5.68)\end{array}$ \\
\hline$S A V E$ & $\begin{array}{l}1.084 \\
(9.84)\end{array}$ & $\begin{array}{l}1.080 \\
(12.62)\end{array}$ & $\begin{array}{l}1.091 \\
(3.72)\end{array}$ \\
\hline$M S A V E$ & $\begin{array}{l}-3.251 \\
(-3.92)\end{array}$ & $\begin{array}{l}-4.103 \\
(-0.59)\end{array}$ & $\begin{array}{l}-3.50 \\
(-3.75)\end{array}$ \\
\hline Adjusted $\mathrm{R}^{2}$ & .250 & .550 & .167 \\
\hline Sample size & 671 & 671 & 671 \\
\hline
\end{tabular}


Table 5. Regression Results for Tournaments without Karrie Webb

\begin{tabular}{|c|c|c|c|}
\hline $\begin{array}{l}\text { Fixed } \\
\text { Effects? }\end{array}$ & No. & $\begin{array}{l}\text { Yes. } \\
\text { Courses. }\end{array}$ & No \\
\hline Constant & $\begin{array}{l}-2318 \\
(-2.74)\end{array}$ & & $\begin{array}{l}-3715 \\
(-4.63)\end{array}$ \\
\hline PRIZE & $\begin{array}{l}-.025 \\
(-3.10)\end{array}$ & $\begin{array}{l}.037 \\
(1.75)\end{array}$ & \\
\hline FIRST & & & $\begin{array}{l}-.578 \\
(-5.14)\end{array}$ \\
\hline OTHER & & & $\begin{array}{l}.057 \\
(3.07)\end{array}$ \\
\hline$P A R$ & $\begin{array}{l}-1.008 \\
(-3.39)\end{array}$ & $\begin{array}{l}2.861 \\
(1.12)\end{array}$ & $\begin{array}{l}-1.638 \\
(-5.32)\end{array}$ \\
\hline$Y A R D S$ & $\begin{array}{l}.028 \\
(4.69)\end{array}$ & $\begin{array}{l}-.041 \\
(-0.60)\end{array}$ & $\begin{array}{l}.040 \\
(6.51)\end{array}$ \\
\hline$S A V E$ & $\begin{array}{l}.700 \\
(3.73)\end{array}$ & $\begin{array}{l}.721 \\
(5.00)\end{array}$ & $\begin{array}{l}.733 \\
(4.14)\end{array}$ \\
\hline$M S A V E$ & $\begin{array}{l}8.170 \\
(2.83)\end{array}$ & $\begin{array}{l}-11.605 \\
(-0.81)\end{array}$ & $\begin{array}{l}14.039 \\
(4.74)\end{array}$ \\
\hline Adjusted $\mathrm{R}^{2}$ & .142 & .503 & .238 \\
\hline Sample size & 191 & 191 & 191 \\
\hline
\end{tabular}




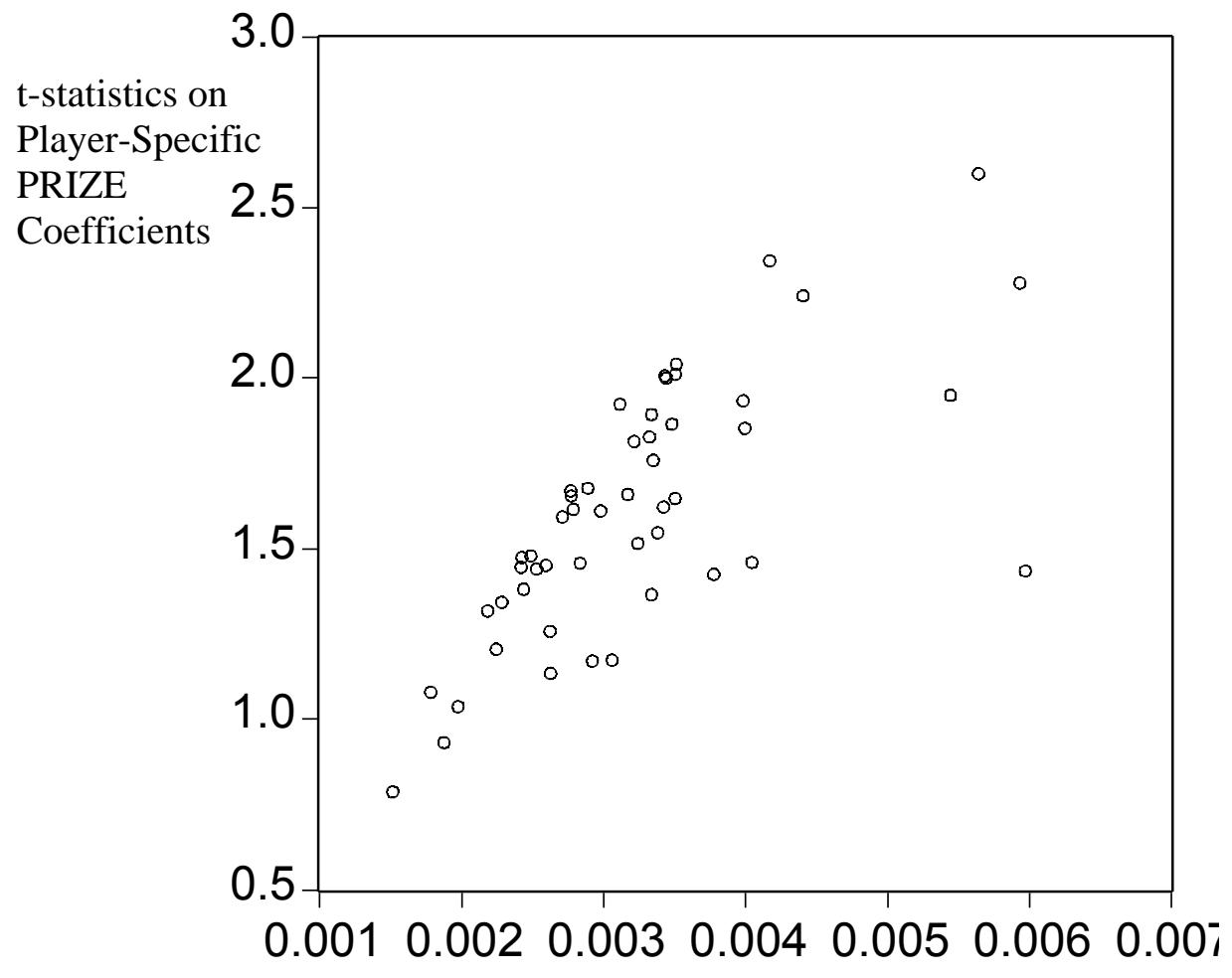

Player-Specific PRIZE Coefficients

Figure 1. PRIZE Coefficients and t-statistics in the Variable Coefficient Model 


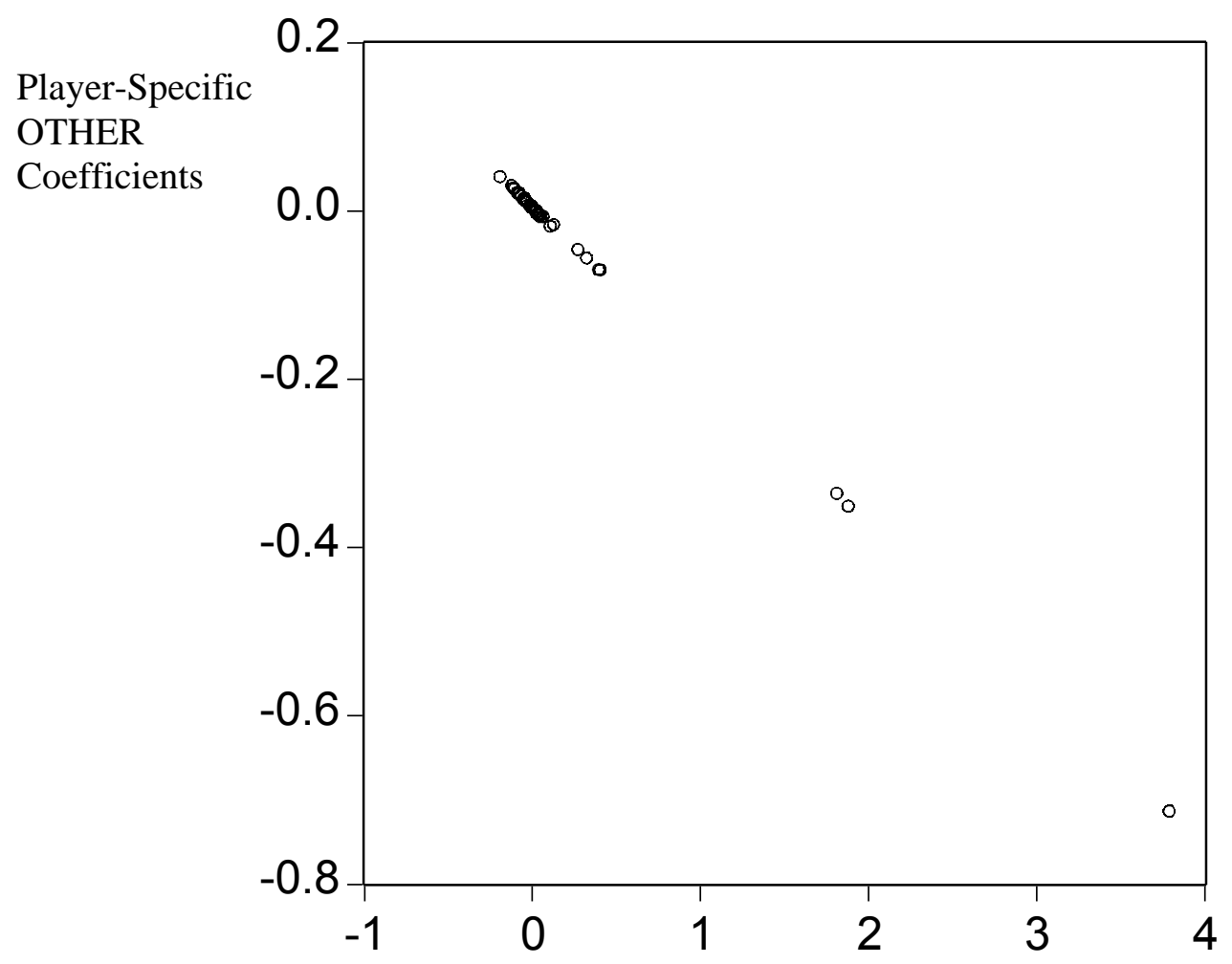

Player-Specific FIRST Coefficients

Figure 2. FIRST and OTHER Coefficients in the Variable Coefficient Two Prize Model 